\title{
Een analyse van de kosten in een probleemgestuurd curriculum
}

\author{
A.J.J.A. Scherpbier, M.E.H. Heckmann, L.F.J.Th.M. Kolle, G.A.J. Dunselman, C.P.M. van der Vleuten
}

\section{Samenvatting}

Froblemgesturd onderwis (PGo) heeft het imago dur onderwis te zin. Een echte kosten-batenanalyse is niet goed mogelijk omat de baten' wan een goede arts niet goed meetbaar zin Uit een analyse van de verdeling van de middelen in Mastrich blikt dat de kosten toe te wijen zin aan onderdelen van het curriculum en de onderwisorganisatie, en dus afhankelik sin van de invulling van het curriculum. Woor een vergeliking tussen faculteiten zin nog te weinig betrouwbare gegevens beschikbaar. Uit onderzoek blikt dat (het Maastichtse) PGO baten oplevert. Om kosten beheersbar te houden word geadviserd om - voorzover mogelik - bji beleidsbesiuten kosten-batenanalyses een rol te laten spelen. Daanast is het planen van te veel onderwijs verspilling van geld omdat de studenten niet evenredg meer gaan studeren. Aangeraden word om te onderoeken wat stidenten leren, zodat ongewente biwerkingen van goedbedolde matregelen hersteld kumen worden.

\section{Inleiding}

Het medisch onderwijs is volop in beweging. In alle faculteiten geneeskunde staan curriculumherzieningen op stapel, zijn ze aan de gang of zijn ze de afgelopen jaren uitgevoerd. Hoewel er veel verschillen zijn tussen de (plannen voor) nieuwe curricula, is als gemeenschappelijk kenmerk een verschuiving herkenbaar van docentgecentreerd naar studentgecentreerd onderwijs. Bij deze ontwikkeling hebben de onderwijsvisitaties in 1992 en 1997 een sturende en stimulerende rol gespeeld. ${ }^{2}$ De langste ervaring met studentgecentreerd onderwijs in de vorm van probleemgestuurd onderwijs (PGO) heeft Maastricht, waar in 1974 in een nieuwe faculteit met een nieuw - probleemgestuurd - curriculum begonnen werd. In de andere faculteiten ging en gaat het om recente veranderingen in een historisch gegroeide situatie. Veranderen in een bestaande situatie is buitengewoon moeilijk en het is dan ook bewonderenswaardig indien dergelijke veranderingen lukken.
Studentgecentreerd onderwijs is onderwijs waarbij het leren van de student centraal staat. Het is vormgegeven volgens hedendaagse inzichten over leren. ${ }^{3}$ Leren wordt beschouwd als een actief proces, dat niet voor ieder individu hetzelfde verloopt. De student wordt beschouwd als een volwassene. Uit de cognitieve psychologie weten we dat de student een goed functionerend kennisnetwerk moet ontwikkelen om kennis te kunnen toepassen. Voor de ontwikkeling van dat netwerk zijn de volgende factoren belangrijk: kennis moet verworven worden in een context die lijkt op de situatie waarin de kennis later toegepast zal worden; misvattingen moeten hersteld kunnen worden; onderwerpen moeten herhaald worden in een andere, relevante context en/of met een andere moeilijkheidsgraad. ${ }^{4}$ Vertaald naar de onderwijspraktijk betekent dit dat studentgecentreerd onderwijs veelal kleinschalig onderwijs is, waarbij de student een actieve rol heeft, zelf verantwoordelijk is, zelf bepaalt of onderwijs gevolgd wordt en mogelijkheden heeft om zelf informatie 
te verzamelen. ${ }^{3}$ Dit laatste betekent dat studenten toegang moeten hebben tot goede bibliotheekfaciliteiten en andere informatievoorzieningen. De studenten moeten ook voldoende tijd hebben om te studeren. In een studentgecentreerd curriculum wordt daarom maar een beperkt gedeelte van de week onderwijs aangeboden. Een van de argumenten hiervoor is dat uit onderzoek gebleken is dat naarmate de onderwijscontacttijd toeneemt, de tijd die besteed wordt aan zelfstudie, afneemt. 5 In het rapport van de Commissie Wijnen over studeerbaarheid wordt geadviseerd om te streven naar een verhouding van $30-40 \%$ onderwijsdeelname en 60 $70 \%$ zelfstudie. 6

In een docentgecentreerd curriculum wordt de inhoud van het onderwijs bepaald door het hoofd van een vakgroep of de individuele docent die het onderwijs geeft. Dit kan leiden tot ongewenste overlap, afstemmingsproblemen en hobbyisme. Om te bewerkstelligen dat het leren en studeren van de student ook echt centraal staan, moet het curriculum zorgvuldig opgebouwd en aangestuurd worden. Een voorwaarde voor studentgecentreerd onderwijs is een slagvaardige onderwijsorganisatie die het grote geheel bewaakt.

De eerste indruk die deze beschrijving wekt, is dat studentgecentreerd onderwijs wel eens duur onderwijs zou kunnen zijn. Een kosten-batenanalyse is nodig om na te gaan of die indruk klopt. De baten van geneeskundeonderwijs op de lange termijn bestaan uit goede artsen. Het probleem is dat deze baten niet goed meetbaar zijn. Op voorhand is daarom duidelijk dat een volledige analyse niet mogelijk is. In dit artikel wordt desalniettemin gezocht naar een zo goed mogelijk antwoord op de vraag of probleemgestuurd onderwijs (een vorm van studentgecentreerd onderwijs) duur is en, zo ja, welke onderdelen het duur maken. De auteurs baseren zich daarbij op hun eigen eerste ervaringen met het 'rekenen' aan het Maastrichtse PGO, op literatuur en op onderzoeksbevindingen. Ook wordt aandacht besteed aan (de problemen bij) interfacultaire vergelijkingen. Omdat het begrip PGO niet eenduidig is, wordt eerst uitgelegd hoe het curriculum in Maastricht in elkaar zit. 78 Tot slot wordt een aantal aanbevelingen gedaan hoe de kosten van een (studentgecentreerd) curriculum beheersbaar te houden.

\section{Het curriculum in Maastricht}

Het curriculum duurt zes jaar. De laatste twee jaar bestaan uit praktische stages, de co-assistentschappen, in het academisch ziekenhuis, de geaffilieerde ziekenhuizen en de eerste lijn. Inhoud en vormgeving zijn (in grote lijnen) vergelijkbaar met die van de co-assistentschappen in andere faculteiten geneeskunde. Verspreid over de zes studiejaren wordt ongeveer een jaar besteed aan keuzeonderwijs. Het onderwijs in de eerste vier jaar bestaat uit blokken van vier tot zes weken rondom een bepaald thema. Een blok wordt samengesteld en gecoördineerd door een multidisciplinair samengestelde blokplanningsgroep. In een blok worden verschillende onderwijsvormen toegepast. Een centrale rol hebben de onderwijsgroepen, bestaand uit negen studenten en een docent, die tweemaal per week bijeenkomen. In de onderwijsgroepsbijeenkomsten worden problemen besproken die zoveel mogelijk gebaseerd zijn op echte praktijkproblemen. De studenten kunnen nagaan wat ze al weten en of wat ze weten correct is en van voldoende diepgang en samenhang. Op grond hiervan bepaalt de student wat hij of zij nog (eens) moet uitzoeken. De docent speelt in dit proces een begeleidende rol. Het product van de onderwijsgroepsbijeenkomst bestaat uit individuele leerdoelen waarover studenten in de volgende bijeenkomst rapporteren. Naast de 
onderwijsgroepen zijn er in de eerste vier jaar colleges, practica, vaardigheidsonderwijs en (niet in elk blok) contacten met de praktijk van de gezondheidszorg. $\mathrm{Na}$ afloop van een blok wordt een bloktoets afgenomen. Verder wordt vier keer per jaar bij alle studenten uit alle studiejaren dezelfde voortgangstoets afgenomen. Deze toets is afgestemd op het eindniveau van de opleiding, en de prestaties van de studenten blijken dan ook in de loop van de opleiding steeds beter te worden. Met uitzondering van het vijfde jaar, wordt in elk studiejaar een vaardigheidstoets afgenomen. De inhoud van deze toets is cumulatief: aan het einde van het eerste jaar worden de vaardigheden getoetst die studenten in het eerste jaar geleerd hebben, aan het einde van het tweede jaar de vaardigheden van het eerste en tweede jaar, et cetera.

\section{Verdeling van onderwijsmiddelen in Maastricht}

De verschillende functies van docenten in onderwijsrollen zijn beschreven en er is voor elke functie een aantal uur beschikbaar. ${ }^{9}$ Dit wordt wel eens ervaren als bureaucratisch, maar in feite is dit de enige manier om taken goed te kunnen verdelen over vakgroepen. Ook biedt deze duidelijkheid aanknopingspunten voor gesprekken over kwantiteit én kwaliteit en de mogelijkheid om bij discussies over onderwijsbeleid het kosten-en-batenaspect een rol te laten spelen. Deze mogelijkheden worden tot nu toe nog te beperkt gebruikt. De hier beschreven gegevens en de daarop gebaseerde adviezen vormen een aanzet tot een nieuwe benadering van onderwijsbeleid, die wij in de opleiding geneeskunde in Maastricht aan het introduceren zijn.

De hoeveelheid personeel beschikbaar voor onderwijs staat op de facultaire personeelsbegroting in fulltime equivalents (fte) vermeld. In geld uitgedrukt is er voor wetenschappelijk personeel (WP) 11.786 $\mathrm{kf}$ (80 fte) en voor niet-wetenschappelijk personeel (NWP) $3.853 \mathrm{kf}$ (44 fte) gereserveerd. Daarnaast wordt een deel van de personeelslasten (met name de vergoedingen voor de co-assistentschappen buiten het academisch ziekenhuis) via de exploitatiebegroting vergoed. In de begroting worden ook de kosten voor de exploitatie en afschrijving van apparatuur opgevoerd. In totaal gaat het om $5.108 \mathrm{kf}$. In het kader van de werkplaatsfunctie wordt door het academisch ziekenhuis een onderwijsinspanning geleverd in de co-assistentschappen. De omvang hiervan en van de ermee samenhangende exploitatiekosten zijn niet precies bekend, omdat in de betreffende documenten geen uitsplitsing gemaakt wordt in onderwijs en onderzoek. Kosten van ruimten, restauratieve voorzieningen, schoonmaak, bibliotheek, et cetera worden hier buiten beschouwing gelaten. Omdat het bij de verdeling niet om absolute getallen gaat en omdat niet alle gegevens bekend zijn, worden in de analyse percentages gebruikt. In figuur 1 is de relatieve verdeling van de totale middelen over de verschillende onderdelen van het onderwijs weergegeven. De getallen staan in tabel 1 in de kolom 'Totaal'. Daar is voor elk onderdeel weergegeven welk percentage van het totale onderwijsbudget eraan wordt besteed. In de overige kolommen wordt aangegeven hoe dit percentage is verdeeld over de kosten voor WP, NWP en exploitatie. Voor het NWP moet daarbij opgemerkt worden dat de verdeling vertroebeld wordt doordat een deel van de NWP-formatie niet op taken is gebaseerd, maar modelmatig is gekoppeld aan de WP-formatie; de overige NWP-formatie wordt wel specifiek toegekend. Voor het WP moet nog opgemerkt worden dat het onderwijs in de co-assistentschappen, zoals eerder vermeld, deels via de exploitatiebegroting wordt vergoed. 
Figuur 1. Verdeling middelen over onderwijsonderdelen.

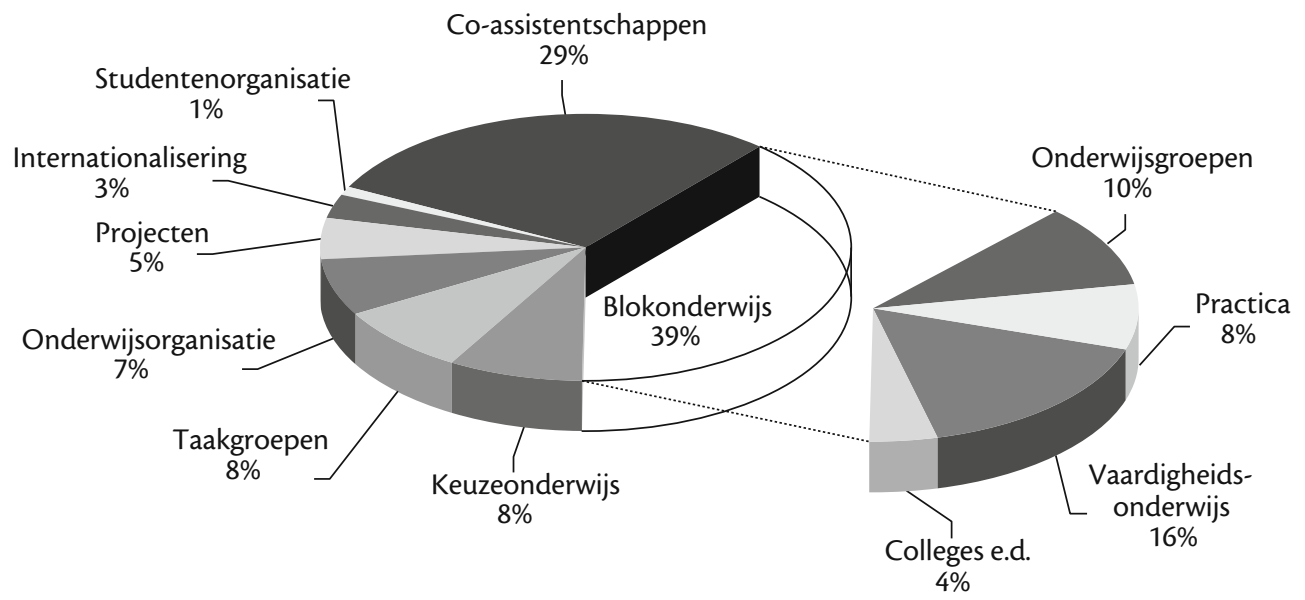

Aan het totale blokonderwijs in de eerste vier studiejaren wordt bijna veertig procent van de middelen besteed. Als gekeken wordt naar de vier onderdelen van het blokonderwijs, blijkt dat ruim tien procent wordt besteed aan de onderwijsgroepen en de coördinatie van dit onderwijs, ruim acht procent aan practica en zestien procent aan vaardigheidsonder- wijs en praktijkcontacten. De resterende vier procent wordt besteed aan colleges, et cetera. Uit deze onderverdeling blijkt dat de formatie voor blokonderwijs voor het grootste gedeelte wordt besteed aan onderwijs in kleine groepen (practica, vaardigheidsonderwijs en onderwijsgroepen). Als de besteding van de middelen wordt uitgesplitst over WP, NWP en

Tabel 1. Verdeling van de beschikbare middelen over de verschillende onderdelen van het onderwijs met een uitsplitsing in middelen voor WP, NWP en exploitatie. Alle getallen zijn percentages van het totale onderwijsbudget (20.748 kf).

\begin{tabular}{lrrrr}
\hline & WP & NWP & Exploitatie & Totaal \\
\cline { 2 - 5 } Blokonderwijs & & & & \\
- Onderwijsgroepen en coördinatie & 8.5 & 0.9 & 1.0 & 10.4 \\
- Practica & 4.0 & 2.9 & 1.5 & 8.4 \\
- Vaardigheidsonderwijs en praktijk & 10.8 & 3.3 & 2.0 & 16.1 \\
• Colleges en dergelijke & 4.0 & 0.4 & - & 4.4 \\
Keuzeonderwijs & 5.1 & 1.5 & 1.0 & 7.6 \\
Co-assistentschappen & 15.3 & 2.8 & 11.0 & 29.1 \\
Taakgroepen & 4.0 & 2.6 & 1.7 & 8.3 \\
Onderwijsorganisatie & 2.3 & 3.3 & 1.3 & 6.9 \\
Projecten & 2.8 & - & 2.2 & 5.0 \\
Internationalisering & - & 0.8 & 1.8 & 2.6 \\
Studentenorganisatie & - & - & 1.2 & 1.2 \\
& & & & \\
\hline
\end{tabular}


exploitatie (tabel 1), blijkt dat de kosten voornamelijk uit personeelskosten bestaan. Voor de onderwijsgroepen is dat voornamelijk WP. Bij practica en vaardigheidsonderwijs wordt ook NWP ingezet. Voor dit onderwijs is NWP-formatie specifiek toegewezen. Omdat leren in de context van de latere beroepsuitoefening van belang blijkt te zijn, kunnen de uitgaven voor vaardigheidsonderwijs en praktijkcontacten verdedigd worden. Of de uitgaven voor practica verantwoord zijn, is moeilijk te bepalen. Intern zijn de meningen daarover verdeeld. Wat betreft de invulling (en dus de kosten) van het blokonderwijs is de vraag actueel of er niet te veel onderwijs is gepland. Er is de afgelopen jaren veel bijgekomen en niets afgegaan. Wellicht bestaat er een verband tussen de toename van gepland onderwijs en de - in de laatste jaren gesignaleerde afname van de tijd die studenten aan zelfstudie besteden. Eerder in dit artikel is reeds gewezen op de relatie tussen zelfstudie en geprogrammeerd onderwijs. 6

Ongeveer acht procent van de middelen wordt besteed aan keuzeonderwijs. Zoals beschreven, wordt ongeveer een jaar van het curriculum hieraan besteed. In vergelijking met de kosten van het blokonderwijs, waaraan - verspreid over vier studiejaren - drie jaar wordt besteed, en de co-assistentschappen, die twee jaar in beslag nemen, is het keuzeonderwijs relatief goedkoop. De NWP-inzet is voor een deel specifiek toegewezen voor de administratieve organisatie van het onderwijs. Een aanzienlijk deel van het keuzeonderwijs wordt in het buitenland gevolgd en er is dan ook overlap met het onderdeel internationalisering. Als de kosten van het uitzenden van studenten naar het buitenland en de kosten van de keuzeco-assistentschappen meegeteld worden bij het keuzeonderwijs, stijgt het percentage.
De kosten voor de co-assistentschappen vormen bijna dertig procent van de totale begroting. Dit bedrag is in werkelijkheid aanzienlijk hoger: zoals eerder beschreven, wordt in het academisch ziekenhuis nog een extra inspanning geleverd. Als rekening gehouden wordt met alle budgetten, zijn de co-assistentschappen in feite het duurste onderdeel van het curriculum. Er is al langere tijd, en in alle faculteiten, kritiek op de invulling van deze fase van de opleiding. ${ }^{2}$ Uit de kritiek blijkt dat bij de vormgeving en invulling van de co-assistentschappen het leren van de student niet centraal staat, maar dat vele andere factoren bepalend zijn (geweest). In het licht van de verdeling van de middelen wordt deze kritiek nog pregnanter en wordt de noodzaak tot verbetering nog duidelijker dan die al was.

Aan de taakgroepen (programma-evaluatie, toetsing, docentenprofessionalisering, studieadvisering, en media en technologie) wordt ongeveer acht procent van de middelen besteed. De kosten van NWPinzet en exploitatie worden voor het grootste gedeelte veroorzaakt door de uitvoering en organisatie van de toetsen. Aan de onderwijsorganisatie wordt zeven procent van de middelen besteed. In werkelijkheid is dit percentage hoger, omdat voor de vraagstelling van dit artikel is geprobeerd om de kosten zo goed mogelijk terug te rekenen naar de onderdelen van het curriculum. Zoals te verwachten bij een onderdeel waarin veel georganiseerd wordt, is de post NWP het grootste onderdeel van de kosten. Aan tijdelijke vernieuwingsprojecten wordt vijf procent van de middelen besteed. Deze post zal de komende tijd stijgen, omdat onderwijsontwikkeling projectmatig zal worden aangepakt. De middelen hiervoor worden deels vrijgemaakt uit de staande organisatie. Daarnaast worden extra middelen gezocht voor een curriculumvernieuwing. Aan interna- 
tionalisering wordt ongeveer drie procent van de totale middelen besteed. Zoals eerder beschreven, is er enige overlap met de middelen voor het keuzeonderwijs. Het resultaat voor studenten is heel positief. Er hebben in het studiejaar 1998/1999 bijvoorbeeld 209 studenten in het buitenland onderwijs gevolgd en 63 buitenlandse studenten hebben in Maastricht onderwijs gevolgd. Tot slot, maar zeker niet onbelangrijk, wordt één procent van de middelen aan studentenorganisaties besteed. De kosten bestaan uit vergoedingen voor de studenten die functies bekleden in de onderwijsorganisatie (opleidingscommissie, examencommissie, et cetera). Ook worden studentenorganisaties gesubsidieerd. Het besluit om een vergoeding te betalen aan studenten die een rol spelen in het onderwijsorganisatie, bevestigt het belang dat de faculteit hecht aan de inbreng van studenten. ${ }^{10}$

\section{Interfacultaire vergelijking}

Informatie over een deel van de kosten, namelijk het aantal fte WP dat in de faculteiten aan onderwijs besteed wordt, is te vinden in de rapporten van de visitatiecommissies. ${ }^{2} 2$ Op basis van de gegevens over de inzet van WP uit het eerste visitatierapport is een kosten-batenanalyse uitgevoerd. ${ }^{11}$ De auteurs concluderen dat de - in vergelijking met andere faculteiten hogere kosten in Maastricht toe te schrijven zijn aan de extra aandacht voor vaardigheidsonderwijs, studentenbegeleiding en docentenprofessionalisering. Als er rekening gehouden wordt met de baten, is PGO volgens de auteurs effectief en attractief. ${ }^{11}$ Sefton concludeert ook dat PGO niet duurder is dan traditioneel onderwijs. ${ }^{12}$ De tweede visitatiecommissie uit 1997 constateert dat de informatie van de verschillende faculteiten niet goed vergelijkbaar is, en dat er dus geen conclusies aan verbonden kunnen worden. ${ }^{2}$
De commissie vraagt zich af of alle opgevoerde onderwijs-fte's ook werkelijk ingezet worden voor onderwijs. Een andere reden waarom de getallen niet goed vergelijkbaar zijn, is dat een deel van de kosten van de co-assistentschappen vergoed wordt via de begroting van het academisch ziekenhuis in het kader van de werkplaatsfunctie. Hierover worden lokaal afspraken gemaakt tussen faculteit, universiteit en academisch ziekenhuis. De visitatiecommissie heeft deze informatie niet verzameld. Voor een goede vergelijking is ook inzicht nodig in het aantal fte's NWP, apparatuurbegrotingen, kosten van ruimten en exploitatiebegrotingen.

Wat weten we wel van de baten? Uit het eerder geciteerde visitatierapport blijkt dat het numerieke studierendement van het Maastrichtse onderwijs, landelijk gezien, het hoogst is. ${ }^{2}$ Als de gegevens uit 1992 en 1997 vergeleken worden, blijkt dat de rendementen bij de meeste faculteiten in deze periode gestegen zijn. Of rendement een goed criterium is, wordt door docenten nogal eens betwijfeld. Deze twijfel wordt veelal ingegeven door de intuïtieve associatie van hoog rendement met makkelijke tentamens. Uit het interfacultaire vergelijkend onderzoek dat tot nu toe gedaan is, blijkt echter dat Maastrichtse studenten vergeleken met hun collegae evenveel weten en vaardiger zijn. $81314 \mathrm{Er}$ zijn bovendien aanwijzingen dat studenten uit faculteiten met studentgecentreerde curricula beter in staat zijn om klinische problemen op te lossen. 1516 Een andere onderzoeksbevinding die tegen bovengenoemde intuïtieve associatie pleit, is dat gebleken is dat het rendement voornamelijk bepaald wordt door een doordachte onderwijsprogrammering, een daarop aansluitende toetsprogrammering en een transparante examenregeling. ${ }^{2} 17$ Rendement geeft dus niet zonder meer een indicatie van het bereikte niveau, al is de 
associatie hoog rendement-laag niveau niet gefundeerd. Een goede inschatting van de baten van PGO is alleen mogelijk als er gegevens zijn over het rendement en het niveau. Voor het bepalen van het niveau is interfacultair onderzoek nodig.

\section{Discussie}

De vraag of probleemgestuurd onderwijs duur is, kan niet eenduidig beantwoord worden. Voor een complete kosten-batenanalyse ontbreken er te veel gegevens en hetzelfde geldt voor een vergelijking met ander, niet-probleemgestuurd onderwijs. Er zijn studies gepubliceerd waarin gesteld wordt dat er geen verschil is in kosten tussen PGO en niet-PGO.11 12 Om de baten van een onderwijssysteem op lange termijn te kunnen vaststellen is het belangrijk om te onderzoeken hoe studenten na de studie in de praktijk functioneren. Dergelijk onderzoek is moeilijk uit te voeren vanwege de vele verstorende variabelen, en omdat niet alle kwaliteiten van een goede dokter meetbaar zijn. Wat we wel weten van de baten is dat het rendement hoger is en dat studenten vaardiger zijn en beter in staat lijken om problemen op te lossen. PGO lijkt ertoe te leiden dat studenten in kortere tijd meer leren, hetgeen zou betekenen dat PGO zelfs duurder mag zijn dan docentgecentreerd onderwijs. Als de trend van de stijging van de rendementen in andere faculteiten doorzet, zal er in dit opzicht op korte termijn geen verschil meer zijn. Het is interessant om in de toekomst te onderzoeken hoe de studenten presteren uit andere faculteiten die nu hun curriculum hebben veranderd of aan het veranderen zijn. Het is ook interessant om van de nieuwe curricula de kosten goed in kaart te brengen en onderling te vergelijken.

Uit de analyses van de Maastrichtse gegevens blijkt dat de kosten afhankelijk zijn van de invulling van het curriculum. Deze bevinding komt overeen met conclu- sies uit een eerder verrichte studie. ${ }^{11} \mathrm{De}$ kosten van bijvoorbeeld de onderwijsgroepen zijn niet hoog in vergelijking tot andere kosten, zoals vaardigheidsonderwijs en practica. De co-assistentschappen zijn in feite het duurste onderdeel van het curriculum. Het is overigens de vraag of betalingen voor de co-assistentschappen op de facultaire begroting thuishoren. Er is door verschillende auteurs bepleit dat dit bij de werkplaatsfunctie van het academisch ziekenhuis hoort. 1819

Op basis van de eigen ervaring van de auteurs en de in dit artikel gepresenteerde gegevens en overwegingen kan een aantal adviezen geformuleerd worden om de kosten te beheersen:

1. Bedenk dat er een efficiëntieprobleem ontstaat als meer dan 30 à 40\% van de week aan contactonderwijs wordt besteed, omdat studenten dan, naar verhouding, minder energie aan zelfstudie zullen gaan besteden.

2. Het is aan te raden om in discussies over de inrichting van het onderwijs het kosten-batenaspect ter sprake te brengen. Docenten blijken in de praktijk niet altijd gewend te zijn om over de kosten (en de baten) na te denken. Het risico is dat het inbrengen van deze aspecten als bureaucratisch en ambtelijk ervaren wordt, maar gezien de eindigheid van de budgetten is besluitvorming niet mogelijk zonder met deze aspecten rekening te houden. Voor lezers die geïnteresseerd zijn in onderwijsmanagement is het artikel van Watson et al. over 'Mission-based budgeting' aan te raden. ${ }^{20}$

3. Evalueer en onderzoek wat de studenten doen. Van tevoren is niet altijd te voorspellen welke effecten bepaalde maatregelen zullen hebben op het leergedrag van studenten. Het curriculum dat docenten hebben bedacht ('curriculum on paper') komt niet altijd over- 
een met het curriculum dat wordt uitgevoerd ('curriculum in action') en met wat studenten werkelijk leren ('experienced curriculum'). ${ }^{21}$ Het is goed dat studenten veel leren buiten het curriculum. Als zij echter weinig leren van wat bedacht is en uitgevoerd wordt, is er een probleem met de verhouding tussen kosten en baten. Als studenten hun tijd besteden aan 'verkeerde en nodeloze' dingen, is dat zonde van het geld.

4. Zorg ervoor dat het gewenste gedrag van studenten ondersteund en gestimuleerd wordt door het toets- en examensysteem.

5. Maak goede afspraken over de inhoud en vaststelling van de beoogde resultaten van een rol of taak in het onderwijs, verbindt consequenties aan het niet nakomen van afspraken en werk met taakstellende begrotingen. ${ }^{20}$

\section{Literatuur}

1. Vereniging van Samenwerkende Nederlandse Universiteiten. Visitatierapport Geneeskunde en Gezondheidswetenschappen. Utrecht: VSNU; 1992.

2. VSNU-Visitatiecommissie Geneeskunde en Gezondheidswetenschappen. Onderwijsvisitatie geneeskunde en gezondheidswetenschappen. Utrecht: Vereniging van Samenwerkende Nederlandse Universiteiten; 1997.

3. Dolmans DHJM, Wolfhagen HAP, Vleuten CPM van der, Wijnen WHFW. Wanneer is onderwijs studentgecentreerd? Medisch Contact 1997;32(29):1045-7.

4. Regehr G, Norman GR. Issues in cognitive psychology: implications for professional education. Acad Med 1996;71:988-1001.

5. Gijselaers WH, Schmidt HG. Effects of quantity of instruction on time spent on learning and achievement. Educational Research and Evaluation 1995;1:183-201.

6. Wijnen WHFW, Wolfhagen HAP, Bie D de, Brouwer OG, Ruijter CTA, Vos P. Te doen of niet te doen? Advies over de studeerbaarheid van onderwijsprogramma's in het hoger onderwijs. Leiderdorp: Graficon; 1992.

7. Vleuten CPM van der, Scherpbier AJJA, Wijnen WHFW, Snellen HAM. Flexibility in learning: a case report on problem-based learning. International Higher Education 1996;1(2):17-24.

8. Scherpbier AJJA. Kwaliteit van vaardigheidsonderwijs gemeten [proefschrift]. Maastricht: Universitaire Pers Maastricht; 1997.

9. Majoor GD, Kolle LFJThM. Faculty planning and control in problem-based learning. Education for Health 1997;10(2):189-97.

10. Visser K, Prince CJAH, Scherpbier AJJA, Vleuten CPM van der, Verwijnen GM. Student participation in educational management and organisation. Med Teach 1998;20(5):451-4.

11. Nieuwenhuijzen Kruseman AC, Kolle LFJThM, Scherpbier AJJA. Problem-based learning at Maastricht: an assessment of cost and outcome. Education for Health 1997;10(2):179-87.

12. Sefton AJ. From a traditional to a problem-based curriculum - estimating staff time and resources. Education for Health 1997;10(2):165-87.

13. Verhoeven BH, Verwijnen GM, Scherpbier AJJA, Holdrinet RSG, Oeseburg B, Bulte JA, Vleuten CPM van der. An analysis of progress test results of PBL and non-PBL students. Med Teach 1998;20(4):310-6.

14. Remmen R. An evaluation of clinical skills training at the medical school of the University of Antwerp [proefschrift]. Antwerpen; 1999.

15. Schuwirth LWT. An approach to the assessment of medical problem solving: computerised casebased testing [proefschrift]. Maastricht: Datawyse Universitaire Pers Maastricht; 1998.

16. Schmidt HG, Machiels-Bongaerts M, Hermans H, Cate ThJ ten, Venekamp R, Boshuizen HPA. The development of diagnostic competence: comparison of a problem-based and integrated and a conventional medical curriculum. Acad Med 1996;71(6):658-65.

17. Cohen-Schotanus J. Effecten van curriculumveranderingen: studiewaardering, studeergedrag, kennis, studiedoorstroom in een veranderd medisch curriculum [proefschrift]. Groningen: Rijksuniversiteit Groningen; 1994.

18. Kramer ME, Schadé E. Behoefte aan 'werkplaatsen' buiten de academische en geaffilieerde ziekenhuizen in de artsopleiding, en financiering daarvan. Ned Tijdschr Geneeskd 1975;139(1):35-9.

19. Holdrinet RSG. Dokters gevraagd. Een reflectie op wetenschap en zorg met betrekking tot medisch onderwijs [oratie]. Nijmegen: Katholieke Universiteit Nijmegen; 1999.

20. Watson RT, Romrell LJ. Mission-based budgeting: removing a graveyard. Acad Med 1999;74(6):62740.

21. Coles CR, Grant JG. Curriculum evaluation in medical and health-care education. Med Educ 1985;19:403-22. 
De auteurs

Frof. dr. AJJ.A Scherpbier, wetenschappelik drecteur wan het onderwijinstitut.

M.E.H. Heckmann beheerder Onderwijsinstitut.

Drs. B. Kolle, hoofa Bureau Onderwis wan het onderwisinstiturt.

Dr. G.AJ. Dunselman, gynaecloog, portefeullehouder onderwijs van het Bestuir.

Frof dr. C.P.M. van der Vleuten, voorzitter Capaciteits-

grop Onderwisonwikkeling on onderwisresearch.
Allen zin verbonden adn de Faculteit der Geneeskunde van de Universiteit Maastricht.

Correspondentieadres:

A.J.J.A Scherpbier, Onderwijsinstitul, Faculteit der Geneeskunde, Postbus 616, 6200 MD Maastricht, E-mail: ascherpbieroifag.unimaas.n?.

\section{Summary}

Froblem-based education has the image of being an expensive form of education. An analysis of the costs and benefits is complicated by the difficulty of measuring the outcome of medical education, i.e good doctors. An analysis of the allocation of education resources at Mastricht Medical School has shown that the costs of education can be apportioned to specific parts ortasks of the curriculum and the eduation organisation. Thus, the costs depend on curricular content and implementation. We lack sufficient reliable data for a comparison across different medical schools. Studies have demonstrated the benefits of problem-based education (at Mastricht) To acheve effective cost control, cost-benefit analyses should be taken into account when policy decisions are made. Planning too many teaching activites is a waste of resources, seeing that stidies have shown that stidents do not stidy harder as more teaching is offered. It is recommended to perform studies of what students actully learn, becase such studes will identify any adverse ffects of weh-intentioned measures. (Scherpbier AJA Heckman MEH, Kolle LFJThM, Dunselman GAJ, Weuten CPM van der. An analysis of the costs of a problembased curriculum. Dutch Joumal of Medical Education 2000; $19(2) 57-65$ ) 